\title{
Study on Fluid-Rock Interaction and Reuse of Flowback Fluid for Gel Fracturing in Desert Area
}

\author{
Tianbo Liang $\mathbb{D}^{1,2}$ Linjie Shao, ${ }^{1,2}$ Erdong Yao $\mathbb{D}^{1,2}$ Jie Zuo, ${ }^{1}$ Xiongfei Liu, ${ }^{1}$ \\ Bao Zhang, ${ }^{3}$ and Fujian Zhou $\mathbb{1}^{1,2}$ \\ ${ }^{1}$ State Key Laboratory of Petroleum Resource and Prospecting, China University of Petroleum, Beijing, China \\ ${ }^{2}$ The Unconventional Natural Gas Institute, China University of Petroleum, Beijing, China \\ ${ }^{3}$ Tarim Oilfield Company, Korla, Xinjiang, China
}

Correspondence should be addressed to Erdong Yao; yaoed@cup.edu.cn and Fujian Zhou; zhouf@@cup.edu.cn

Received 14 September 2017; Revised 20 November 2017; Accepted 14 December 2017; Published 16 January 2018

Academic Editor: Zhenhua Rui

Copyright (C) 2018 Tianbo Liang et al. This is an open access article distributed under the Creative Commons Attribution License, which permits unrestricted use, distribution, and reproduction in any medium, provided the original work is properly cited.

\begin{abstract}
Hydraulic fracturing requires a large volume of fresh water, which is difficult and expensive to obtain in the desert area such as Tarim Basin. Currently, flowback fluid is typically transported to the sewage treatment plant and then discharged after reaching environmental requirements; however, this is not only costly, but also a waste of water resource. Therefore, it is imperative to understand the potential interactions between fracturing fluid and reservoir rock, and then find solutions to reuse the flowback water for subsequent fracturing. In this study, once flowback fluid was directly collected from the field, its chemical compositions were analyzed; then, filtering, decoloring, and chelating methods were chosen to effectively remove or shield the unfavorable reintroduced components. Moreover, $\mathrm{pH}$ value was further tuned during different stages of the recycling process to ensure good gelation and cross-linking properties of guar. Cross-linked guar synthesized with the flowback fluid was evaluated in the lab through shear resistance tests and coreflood tests under the reservoir conditions; results indicated the recycled gel behaved similarly as the original gel, or even better. From this work, a cheap and effective treatment process was proposed to reuse the flowback fluid in the desert area.
\end{abstract}

\section{Introduction}

Hydraulic fracturing enables hydrocarbon production from low-permeability or low-productive reservoirs to be economical. In the US, $51 \%$ of crude oil production and $67 \%$ of natural gas production came from the hydraulically fractured wells in 2015 [1-3]. To fracture the formation, a large volume of water is injected to create a fracture network that provides pathways for hydrocarbon to flow [4-8]. In recent years, fracturing experience from various fields indicates that the larger the volume of water used per well, the more complex the created fracture network, and thus the higher the initial hydrocarbon production rate [9-13]. However, in desert area where water resource is scarce, it is neither economic nor sustainable to fracture the formation with a large volume of fresh water. Therefore, it is imperative to understand the potential interactions between fracturing fluid and reservoir rock and then find solutions to recycle and reuse the flowback water for subsequent fracturing.

During hydraulic fracturing, a large volume of proppants is pumped along with fracturing fluid to prevent fractures being closed. To maximize the proppant-carrying capacity of the fracturing fluid, cross-linked gel is typically used $[4,14-$ 16]; this is attributed to its excellent viscosity and elasticity that can prevent proppants settling [17-19]. However, fracturing fluid can interact with formation minerals and the connate water therein, resulting in high contents of suspended and dissolved solids in the flowback fluid [20,21]. When this flowback fluid is reused, the proppant-carrying capacity of the gel can be seriously weakened. Studies have shown that the dissolved solids can affect the gelation and cross-linking of the gel and thus reduce its viscosity and elasticity [2225]. Therefore, when flowback fluid is recycled and reused to prepare the cross-linked gel for fracturing, all components 
that are unfavorable to its gelation and cross-linking must be removed or shielded. Depending on properties of reservoir and fracturing fluid, these reintroduced components in the flowback fluid may include suspended solids, dissolved solids (i.e., anions and cations), and residual gel breakers. Besides, the $\mathrm{pH}$ value and the density of the fracturing fluid may also need to be tuned to fit the requirements of reservoir stimulation design.

In the US, advanced integrated systems have been reported that can collect and recycle the flowback fluid through oxidation and precipitation methods [26, 27]; however, they are expensive to be used in the Tarim Basin, and similar technology is not yet available in China. Therefore, a simple and effective method is expected to be developed to fill the blank. To remove the suspended solids, sand filtration, flocculation, coagulation, and sedimentation methods are typically used in the field [28-30]. In the field, cost is one of the key factors that determines which technique is the best to be used; therefore, this step was not the focus of this study, and the filtration and adsorption were chosen to remove the suspended solids. To remove the dissolved solids, membrane filtration $[31,32]$, reverse osmosis $[33,34]$, and oxidation treatments [28, 35-37] have been developed; however, they are either energy-intensive or difficult to be equipped in Tarim Basin. Therefore, an easier and cheaper chemical shielding method needs to be proposed and evaluated in the lab.

In this study, after the flowback fluid was directly collected from the field, its components were evaluated in the lab to understand the interaction between the fracturing fluid and the reservoir rock; thus, effective treatments could be wisely chosen for reusing the flowback fluid. The formulation for synthesizing the fracturing fluid with the recycled flowback fluid was optimized by evaluating (1) the gelation and cross-linking properties of gel, (2) the shear resistance of gel under the reservoir temperature, and (3) permeability damage due to gel residuals through coreflood tests.

\section{Materials}

2.1. Flowback Fluid. The target reservoir locates in the piedmont region of Tarim Basin, which is characteristic of desert environment, great reservoir depth (over $3000 \mathrm{~m}$ ), and high reservoir temperature (approximately $140^{\circ} \mathrm{C}$ ) [38-40]. To hydraulically fracture this reservoir, cross-linked guar was used as the fracturing fluid. Flowback fluid was directly collected from the field and then tested in this study to explore its recycling and reuse. Key properties of the flowback fluid that may affect the gelation of guar were firstly analyzed in the lab to design the corresponding treatments for recycling and reusing the fluid. These key properties include the $\mathrm{pH}$ value, the density, contents of the residual breakers, the suspended solids, and the dissolved solids of the fluid. The analysis results are shown in Results and Discussion.

2.2. Original Formulation of the Fracturing Fluid. The fracturing fluid applied in the field contained approximately 0.35 wt.\% high-molecular-weight guar, 0.36 wt.\% cross-linking agent (i.e., organic borate), 0.7 wt.\% cross-linking regulator (i.e., alkali), 1 wt.\% temperature stabilizing agent (i.e., antioxidant), 1 wt.\% flowback surfactant, 1 wt.\% demulsifier, and traces of other additives. To compare the properties of the original gel with the gel synthesized with the recycled flowback fluid, the original fracturing fluid was synthesized in the lab using the same formulation as used in the field.

2.3. Mimicked Formation Brine. In the lab, the mimicked formation brine was prepared with $2 \mathrm{wt} . \%$ potassium chloride, 5.5 wt.\% sodium chloride, 0.45 wt. $\%$ magnesium chloride, and $0.55 \mathrm{wt} . \%$ calcium chloride.

\section{Laboratory Evaluation Methods}

3.1. Cross-Linking Evaluation. Before gel cross-linking, the base fluid was prepared by mixing high-molecular-weight guar with all additives as introduced in the formulation section except the cross-linking agent. As described above, these additives included cross-linking regulator, temperature stabilizing agent, flowback surfactant, demulsifier, and citric acid for tuning the $\mathrm{pH}$ value. The base fluid was stirred for $30 \mathrm{~min}$ and left to rest for another $2 \mathrm{hr}$ for hydrating and swelling. Then, $100 \mathrm{~g}$ base fluid was mixed with $0.15 \mathrm{~g}$ cross-linking agent at a slow stirring speed. The cross-linking time and the morphology of the cross-linked guar were recorded for evaluation.

\subsection{Temperature and Shear Resistance Test. HAAKE Mars-III} rheometer was applied to measure the change of viscosity of the cross-linked guar at a fixed shear rate of $170 \mathrm{~s}^{-1}$ under the reservoir temperature (i.e., $140^{\circ} \mathrm{C}$ ). Guar synthesized from the flowback fluid was compared with the one originally applied in the field. Results can tell if the unfavorable components were removed, and thus if the recycling was effective.

3.3. Coreflood Test. To further evaluate the permeability damage due to different broken/degraded guar systems, coreflood experiments were applied to determine the reduction of rock permeability to the formation brine before and after the gel breaking. Before conducting the coreflood experiment, the reservoir rock sample was cut into smaller cylindrical cores with diameters of $2.5 \mathrm{~cm}$ and lengths of $3.5 \mathrm{~cm}$. For each core sample, its porosity was determined by saturating the dry core with the mimicked formation brine (i.e., material balance), and it was found to be approximately $9 \%$. Detailed information about the porosity of each core sample tested in this work refers to Results and Discussion.

Figure 1 shows the coreflood setup applied in this study. Once a brine-saturated core sample was loaded vertically in the core holder with a confining pressure of $10 \mathrm{MPa}$, an insulation jacket was used to wrap the core holder for controlling the temperature (center in Figure 1). Due to the limitation of this setup, all corefloods were conducted under $90^{\circ} \mathrm{C}$ instead of $140^{\circ} \mathrm{C}$; further testing might be needed to fill this gap. After the system was stabilized, a 3-step coreflood sequence was conducted on this core sample. The broken/degraded guar system has a higher density than the formation brine; to improve the stability of the displacement front during the coreflood, the mimicked fracturing fluid after gel breaking was injected from the bottom to the top of 


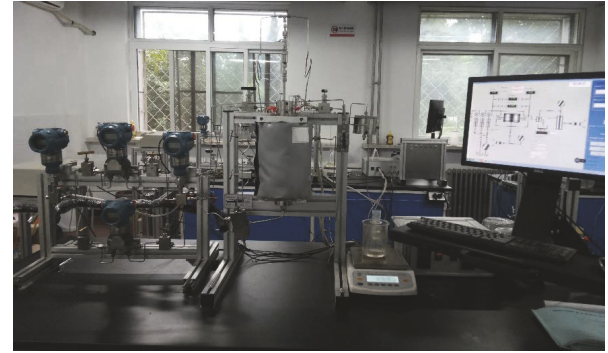

Figure 1: Coreflood setup in the lab.

the core sample while the mimicked brine was injected in the opposite direction [41-43]. Details are as follows.

Step 1 (measure rock permeability to brine before gel damage $\left(\right.$ i.e., $\left.K_{0}\right)$ ). The mimicked formation brine was injected into the core sample at a constant flow rate from the top to the bottom through a piston accumulator by an ISCO pump (not shown in Figure 1); meanwhile, the pressure drop across the core sample was recorded with time by a ROSEMOUNT pressure transducer (left in Figure 1), and the effluent was measured by an electronic balance (right in Figure 1). When the pressure drop and the effluent were stabilized, rock permeability was calculated from Darcy's Law.

Step 2 (simulate rock damage due to the fracturing fluid after gel breaking). To mimic the gel breaking process under the reservoir condition, the cross-linked guar was mixed with $100 \mathrm{ppm}(0.01 \mathrm{wt} . \%)$ ammonium persulfate as the gel breaker. This mixture was then placed in $140^{\circ} \mathrm{C}$ water-bath till the cross-linked gel was completely broken and degraded. After the residual gel was filtered out, it was degassed under the vacuum for $1 \mathrm{hr}$. The final product was the mimicked fracturing fluid after gel breaking at the reservoir condition, and it was defined as Fluid- $X$ in this paper. To mimic the rock damage due to Fluid-X, it was injected into the core sample at a constant flow rate from the bottom to the top through another piston accumulator by the ISCO pump. After 3-5 PVs of Fluid-X was injected through the core, the pump was stopped and the setup was left to rest for another $2 \mathrm{hr}$ at $90^{\circ} \mathrm{C}$.

Step 3 (measure rock permeability to brine after gel damage (i.e., $\left.K_{1}\right)$ ). The mimicked formation brine was injected again into the core sample from the top to the bottom as in Step 1. After the pressure drop across the core sample and the effluent were stabilized, rock permeability was calculated from Darcy's Law.

\section{Results and Discussion}

\subsection{Analysis of Flowback Fluid from the Field}

4.1.1. PH Value and Density. Table 1 shows the change of $\mathrm{pH}$ value and density of the flowback fluid with time from one well in the piedmont region of Tarim Basin. Since this well was previously acidized, the flowback fluid was weakly acidic as shown in this table. The acidic environment is helpful to
TABLE 1: PH values and densities of the flowback fluid in Tarim Oilfield in different flowback periods.

\begin{tabular}{lccc}
\hline Sample number & Sampling time & PH value & Density $(\mathrm{g} / \mathrm{cc})$ \\
\hline 1 & $2015-7-31-02: 00$ & 6.71 & 1.22 \\
2 & $2015-8-1-02: 00$ & 6.36 & 1.173 \\
3 & $2015-8-1-14: 00$ & 6.25 & 1.154 \\
4 & $2015-8-2-02: 00$ & 6.00 & 1.144 \\
5 & $2015-8-3-02: 00$ & 5.93 & 1.131 \\
6 & $2015-8-3-14: 00$ & 5.86 & 1.124 \\
7 & $2015-8-4-02: 00$ & 5.87 & 1.119 \\
8 & $2015-8-5-02: 00$ & 5.79 & 1.108 \\
9 & $2015-8-5-14: 00$ & 5.81 & 1.101 \\
10 & $2015-8-5-19: 00$ & 5.72 & 1.100 \\
11 & $2015-8-6-14: 00$ & 5.85 & 1.096 \\
12 & $2015-8-7-02: 00$ & 5.72 & 1.093 \\
13 & $2015-8-8-02: 00$ & 5.71 & 1.088 \\
\hline
\end{tabular}

the hydration of the guar powder; therefore, no additional operation is required to tune the $\mathrm{pH}$ value for reusing the flowback fluid. In fact, the usage of citric acid in the original formulation can be saved.

For the fluid density, it was above the fresh water since sodium nitrate was used as the weighting agent during hydraulic fracturing. Comparing to the original fracturing fluid whose density was $1.30 \mathrm{~g} / \mathrm{cc}$, the density of the flowback fluid decreased with time, indicating the loss of weighting agent into the formation. When the flowback fluid is reused, additional weighting agent might be needed depending on the fracturing job; however, the dosage can be less than the case using the fresh water.

4.1.2. Total Suspended Solids. The suspended solids can affect the synthesis of cross-linked guar using the flowback fluid, and it may further cause the formation damage once the fluid is used again for fracturing. The flowback fluid was collected at the early time $(<1$ week, Sample $1 \#)$, the mid time $(2-3$ weeks, Sample 2\#), and the late time (4 weeks, Sample 3\#) for testing in this study, and their pictures are shown in Figure 2. To examine the concentration of the suspended solids in each sample, $10 \mathrm{~mL}$ of sample fluid was centrifuged and dried, and the mass of the total suspended solids was then measured by an electronic balance. The results are shown in Table 2 .

4.1.3. Residual Gel Breakers. Since the residual gel breaker can also seriously impact the gelation and cross-linking of guar, its amount in the flowback fluid needs to be examined. In this case, the gel breaker was ammonium persulfate, and potassium iodide was used to detect its existence because their product iodine can turn the starch blue. The chemical reaction equation is shown as follows.

$$
\left(\mathrm{NH}_{4}\right)_{2} \mathrm{~S}_{2} \mathrm{O}_{8}+2 \mathrm{KI}=\left(\mathrm{NH}_{4}\right)_{2} \mathrm{SO}_{4}+\mathrm{K}_{2} \mathrm{SO}_{4}+\mathrm{I}_{2}
$$


TABLE 2: Analysis of total suspended solids and residual gel breakers in the flowback fluid in Tarim Oilfield.

\begin{tabular}{|c|c|c|c|c|c|c|}
\hline Sample Name & $\begin{array}{c}5 \text { ppm } \\
\text { Ammonium } \\
\text { persulfate }\end{array}$ & $\begin{array}{c}10 \text { ppm } \\
\text { Ammonium } \\
\text { persulfate }\end{array}$ & $\begin{array}{c}50 \mathrm{ppm} \\
\text { Ammonium } \\
\text { persulfate }\end{array}$ & $\begin{array}{c}\text { Sample } 1 \# \\
\text { (Early time) }\end{array}$ & $\begin{array}{l}\text { Sample 2\# } \\
\text { (Mid time) }\end{array}$ & $\begin{array}{l}\text { Sample 3\# } \\
\text { (Late time) }\end{array}$ \\
\hline $\begin{array}{l}\text { Total suspended } \\
\text { solid }(\mathrm{mg} / \mathrm{L})\end{array}$ & I & I & I & 530 & 260 & 360 \\
\hline Color change & Blue & Blue & Blue & No change & No change & No change \\
\hline
\end{tabular}

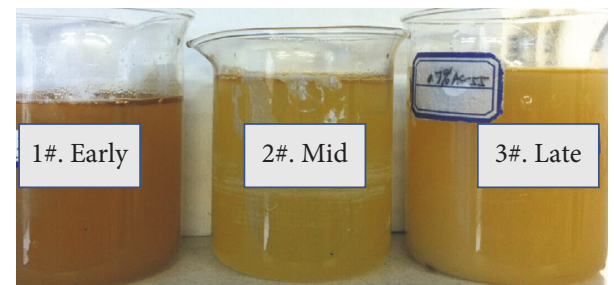

FIGURE 2: Flowback sample collected in different periods (Samples $1 \#-3 \#)$.

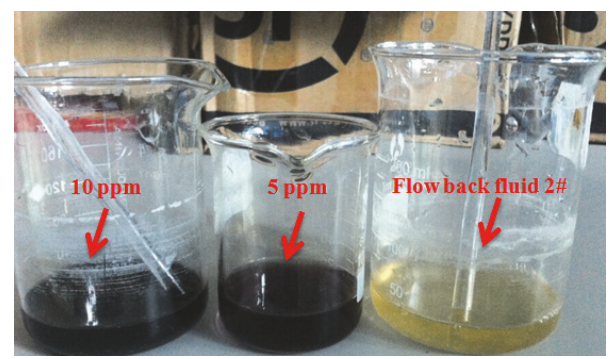

FIGURE 3: Comparison of flowback fluid Sample 2\# with 5 ppm and $10 \mathrm{ppm}$ ammonium persulfate control samples after both potassium iodide and starch were added.

Ammonium persulfate solution was diluted into $5 \mathrm{ppm}$, $10 \mathrm{ppm}$, and $50 \mathrm{ppm}$ as the control groups; they were compared with the filtered samples $1 \#-3 \#$ to estimate the amount of gel breaker therein. Specifically, $2 \mathrm{~g}$ of potassium iodide was added to $20 \mathrm{~mL}$ of each fluid sample; then, $1 \mathrm{wt} . \%$ of starch solution was added to the mixture for observation. Figure 3 shows the comparison of flowback fluid Sample 2\# with two ammonium persulfate control samples (5 ppm and $10 \mathrm{ppm}$ ) after both potassium iodide and starch were added; Table 2 also lists the color test results of all six fluid samples.

Results indicate that this examination method can detect as low as $5 \mathrm{ppm}$ ammonium persulfate in the solution. Since all three flowback fluid samples did not turn blue, the amount of residual gel breaker could be negligible and thus it is unlikely to affect the following recycling process.

4.1.4. Dissolved Solids/Ions from the Formation. Flowback fluid also contains dissolved ions from the formation as well as the formation water. Table 3 lists the change of chloride ion content in the flowback fluid during different flowback periods. The content increased from $30000 \mathrm{ppm}$ and plateaued at $58000 \mathrm{ppm}$ after 8 days. Since the original fracturing fluid contained only trace amounts of chloride ions, high chloride
TABLE 3: Change of chloride ion content in flowback fluid in different flowback periods.

\begin{tabular}{lc}
\hline Flowback time & Chloride ion content $(\mathrm{ppm})$ \\
\hline Day 1 & 32000 \\
Day 2 & 45000 \\
Day 3 & 57000 \\
Day 4 & 57000 \\
Day 5 & 62000 \\
Day 6 & 64000 \\
Day 7 & 62000 \\
Day 8 & 58000 \\
Day 9 & 58000 \\
Day 10 & 58000 \\
\hline
\end{tabular}

ion content in the flowback fluid was attributed to the dissolved solids from the formation. Although not measured here, high cation contents were expected along with the chloride ions, which can be sodium, calcium, magnesium, iron, and other metal ions. These metal ions can seriously affect properties of the cross-linked gel; thus corresponding treatments are necessary for recycling the flowback fluid.

4.2. Removal of Suspended Solids. In the field, sand filtering was typically applied to remove the suspended solid from the flowback fluid; in the lab, this was mimicked by using the filter papers. After flowback fluid samples 1\#-3\# were filtered, they were heated up to $90^{\circ} \mathrm{C}$ with $5 \mathrm{wt} . \%$ activated carbon and stirred for 30-60 min for decoloring.

Figure 4 shows the concentrations of total suspended solids in different flowback samples after filtering and decoloring treatments in the lab, and Figure 5 shows the appearances of these treated fluid samples. Results indicate that filtering can effectively remove the suspended solid, and the decoloring by activated carbon can further remove the suspended solids, achieving similar values as the tap water used in the lab.

4.3. Shielding of Dissolved Solids. The impact of different dissolved ions on the gelation and cross-linking of guar was firstly studied for choosing the target ions to be shielded. To do so, the original formulation as depicted in the section of Materials was mixed with the following chemicals, respectively: 20000 ppm NaCl (Sample TI-1), 20000 ppm $\mathrm{NaNO}_{3}$ (Sample Tl-2), $500 \mathrm{ppm} \mathrm{CaCl}_{2}$ (Sample Tl-3), $500 \mathrm{ppm}$ $\mathrm{MgCl}_{2}$ (Sample Tl-4), and $400 \mathrm{ppm} \mathrm{FeCl}$ (Sample Tl-5).

As shown in Figures 6-10, $\mathrm{Na}^{+}, \mathrm{Cl}^{-}$, and $\mathrm{NO}_{3}{ }^{-}$had negligible effect on the cross-linking of guar, while $\mathrm{Ca}^{2+}, \mathrm{Mg}^{2+}$, 


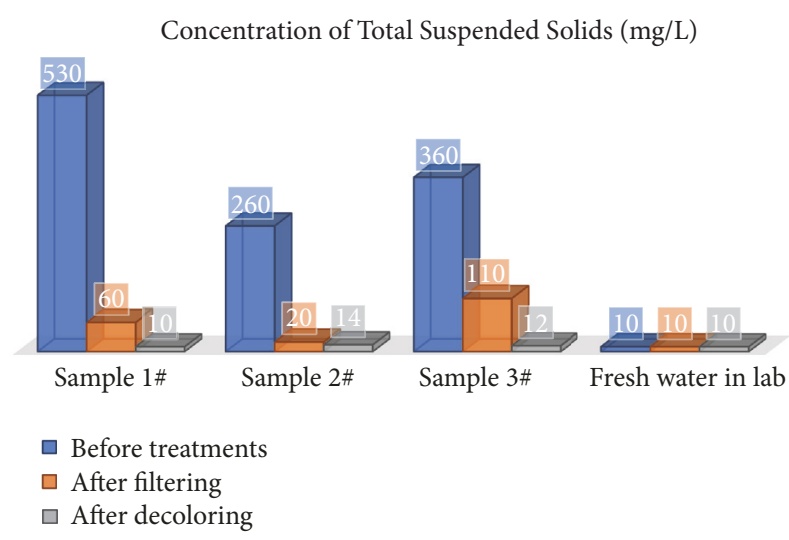

FIgURE 4: Concentrations of total suspended solids in different flowback samples (1\#-3\#) after filtering and decoloring treatments in the lab.

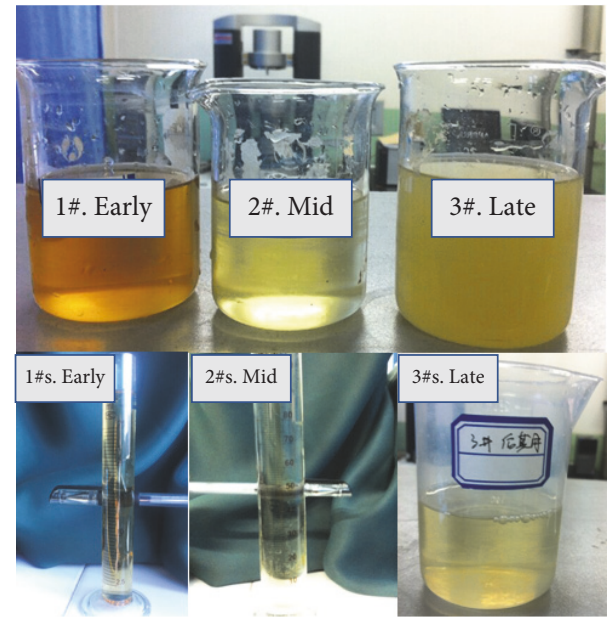

FIGURE 5: Flowback fluid samples (1\#-3\#) after filtering and decoloring treatments.

and $\mathrm{Fe}^{2+}$ all dramatically reduced the elasticity of the crosslinked guar. Since the elasticity of fracturing fluid may enhance its ability to transport proppants $[18,44,45]$, these divalent metal ions need to be shielded when the flowback fluid is recycled and reused.

To shield these divalent metal ions, two types of chelating agents with different concentrations were chosen and compared, and they are EDTA and Gl-47S. As compared in Table 4, when sufficient EDTA or Gl-47S was added, the gelation and cross-linking of guar became normal, and the crosslinked gel showed excellent elasticity; for every additional $500 \mathrm{ppm}$ of $\mathrm{Ca}^{2+}, \mathrm{Mg}^{2+}$, or $\mathrm{Fe}^{2+}$, an additional $1000 \mathrm{ppm}$ of EDTA or Gl-47S was needed. For the collected flowback fluid in this study, adding $0.1 \mathrm{wt} . \%$ Gl-47S was sufficient to shield the dissolved divalent metal ions brought from the formation. The cross-linking time was slightly different for two chelating agents; the best $\mathrm{pH}$ value for gel cross-linking was found to be 8 for EDTA, and 9 for Gl-47S.

Combining all analysis results, the optimized formulation for recycling and reusing the flowback fluid from

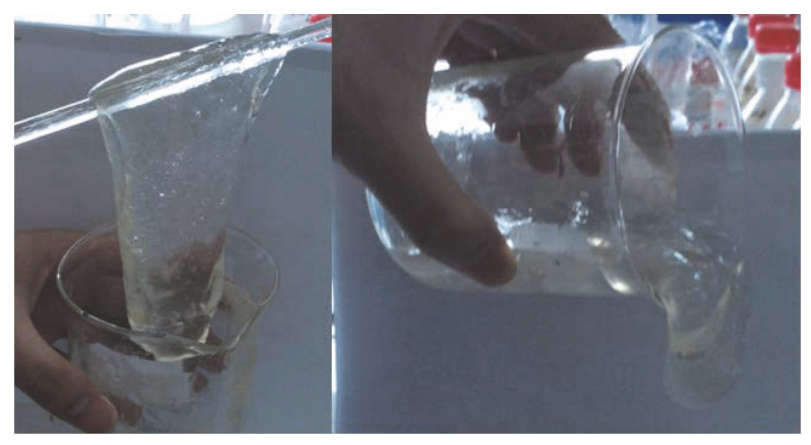

FIGURE 6: Cross-linking of guar with 20000 ppm NaCl (Sample TI$1)$.

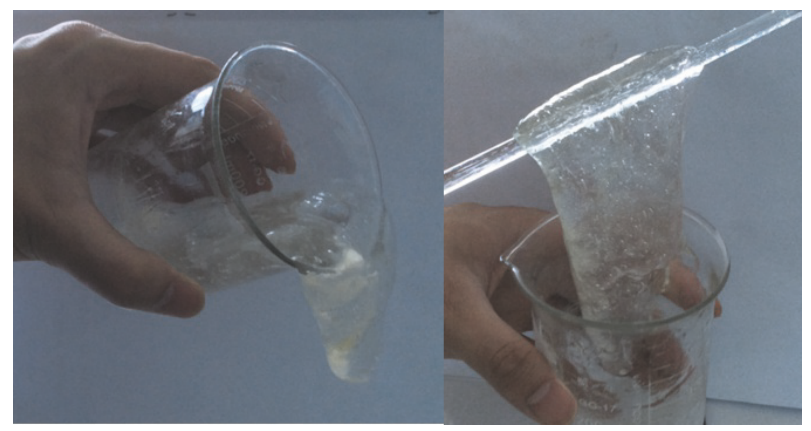

Figure 7: Cross-linking of guar with 20000 ppm $\mathrm{NaNO}_{3}$ (Sample TI-2).

this well/oilfield was found to be filtered flowback fluid + 0.1 wt.\% Gl-47S + 0.03 wt.\% citric acid (tune $\mathrm{pH}$ value to 5) +0.35 wt. $\%$ high-molecular-weight guar +0.3 wt. $\%$ crosslinking regulator (tune $\mathrm{pH}$ value back to 9 ) $+0.36 \mathrm{wt} . \%$ crosslinking agent $+1 \mathrm{wt} . \%$ temperature stabilizing agent $+1 \mathrm{wt} . \%$ flowback surfactant +1 wt.\% demulsifier + traces of other additives as in the original formulation.

4.4. Evaluation of Temperature and Shear Resistance. Figure 11 compares the shear resistance of the cross-linked guar synthesized using the original formulation (a) or using the recycling formulation (b) under the reservoir temperature $\left(140^{\circ} \mathrm{C}\right)$. It can be noticed that peaks showed at the early time of both measurements, and this is likely because the guar and cross-linkers were not sufficiently mixed yet. Nevertheless, the late-time viscosity when temperature reached $140^{\circ} \mathrm{C}$ was the key of this shear resistance test. As shown in this figure, the late-time viscosity of the original fracturing fluid was approximately $200 \mathrm{mPa} \cdot \mathrm{s}$, while the late-time viscosity of the recycled fracturing fluid was approximately $250 \mathrm{mPa}$.s. The recycled guar instead showed a better temperature and shear resistance comparing to the original guar; this indicates the success of the recycling treatment proposed in this study.

4.5. Evaluation of Permeability Damage due to Gel Residuals. Coreflood test can evaluate the comprehensive impact of fracturing fluid on the reservoir rock, from including clay swelling, fine migration, water blockage, and clogging of residuals. Using the coreflood method introduced in the 
TABLE 4: Gelation and cross-linking tests for removing different divalent metal ions.

\begin{tabular}{|c|c|c|c|}
\hline Formulations & $\begin{array}{c}\text { Concentrations of } \\
\text { divalent metal ions } \\
(\mathrm{ppm})\end{array}$ & $\begin{array}{c}\text { Concentrations of } \\
\text { EDTA or GL-47S } \\
(\mathrm{ppm})\end{array}$ & Results \\
\hline \multirow{3}{*}{$\begin{array}{l}\text { IT-6 } \\
\left(\mathrm{CaCl}_{2} \text { with EDTA }\right)\end{array}$} & 200 & 1000 & \multirow{3}{*}{$\begin{array}{l}\text { Normal cross-linking } \\
\qquad(\mathrm{PH}=8)\end{array}$} \\
\hline & 500 & 2000 & \\
\hline & 1000 & 4000 & \\
\hline \multirow{3}{*}{$\begin{array}{l}\text { IT-7 } \\
\left(\mathrm{CaCl}_{2} \text { with Gl-47S) }\right.\end{array}$} & 200 & 1000 & \multirow{3}{*}{$\begin{array}{l}\text { Normal cross-linking } \\
\qquad(\mathrm{PH}=9)\end{array}$} \\
\hline & 500 & 2000 & \\
\hline & 1000 & 4000 & \\
\hline \multirow{3}{*}{$\begin{array}{l}\text { IT-8 } \\
\left(\mathrm{MgCl}_{2} \text { with EDTA }\right)\end{array}$} & 200 & 1000 & \multirow{3}{*}{$\begin{array}{l}\text { Normal cross-linking } \\
\qquad(\mathrm{PH}=8)\end{array}$} \\
\hline & 500 & 2000 & \\
\hline & 1000 & 4000 & \\
\hline \multirow{3}{*}{$\begin{array}{l}\text { IT-9 } \\
\left(\mathrm{MgCl}_{2} \text { with Gl-47S) }\right.\end{array}$} & 200 & 1000 & \multirow{3}{*}{$\begin{array}{l}\text { Normal cross-linking } \\
\qquad(\mathrm{PH}=9)\end{array}$} \\
\hline & 500 & 2000 & \\
\hline & 1000 & 4000 & \\
\hline \multirow{3}{*}{$\begin{array}{l}\text { IT-10 } \\
\left(\mathrm{FeCl}_{2} \text { with EDTA) }\right.\end{array}$} & 40 & 1000 & \multirow{3}{*}{$\begin{array}{l}\text { Normal cross-linking } \\
\qquad(\mathrm{PH}=8)\end{array}$} \\
\hline & 400 & $>2000$ & \\
\hline & 600 & & \\
\hline \multirow{3}{*}{$\begin{array}{l}\text { IT-11 } \\
\left(\mathrm{FeCl}_{2} \text { with Gl-47S) }\right.\end{array}$} & 40 & 1000 & \multirow{3}{*}{$\begin{array}{l}\text { Normal cross-linking } \\
\qquad(\mathrm{PH}=9)\end{array}$} \\
\hline & 400 & $>2000$ & \\
\hline & 600 & & \\
\hline
\end{tabular}

TABLE 5: Comparison of rock permeability damage due to different fracturing fluids.

\begin{tabular}{lccccc}
\hline Formulations & Rock sample & Porosity (\%) & $\begin{array}{c}\text { Permeability before } \\
\text { damage } K_{0}(\mathrm{mD})\end{array}$ & $\begin{array}{c}\text { Permeability after } \\
\text { damage } K_{1}(\mathrm{mD})\end{array}$ & $\begin{array}{c}\text { Damage ratio } \\
\eta(\%)\end{array}$ \\
\hline \multirow{2}{*}{ Broken/degraded recycled guar } & SH11\# & 9.63 & 0.0121 & 0.0087 & 28.10 \\
& SH7\# & 9.10 & 0.0331 & 0.0231 & 30.21 \\
\multirow{2}{*}{ Broken/degraded original guar } & Or1\# & 5.17 & 0.7609 & 0.6860 & 0.8188 \\
& Or6\# & 8.66 & 1.0188 & 19.63 \\
\hline
\end{tabular}

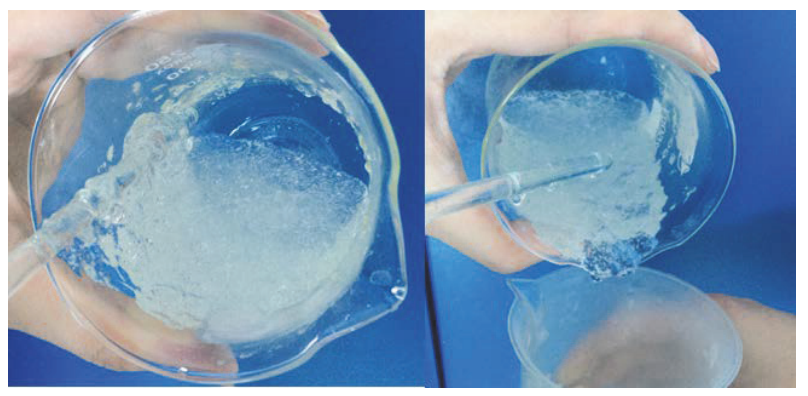

FIGURE 8: Cross-linking of guar with $500 \mathrm{ppm} \mathrm{CaCl}_{2}$ (Sample TI-3).

section of Laboratory Evaluation Methods, four rock samples were tested to compare the permeability damage due to the degraded original guar and the degraded recycled guar, as shown in Table 5. The damage ratios were all higher in the cases when the recycled guar was used; gel residuals and other fluid additives are likely more sensitive to smaller pores/pore throats in rocks with lower permeabilities, where

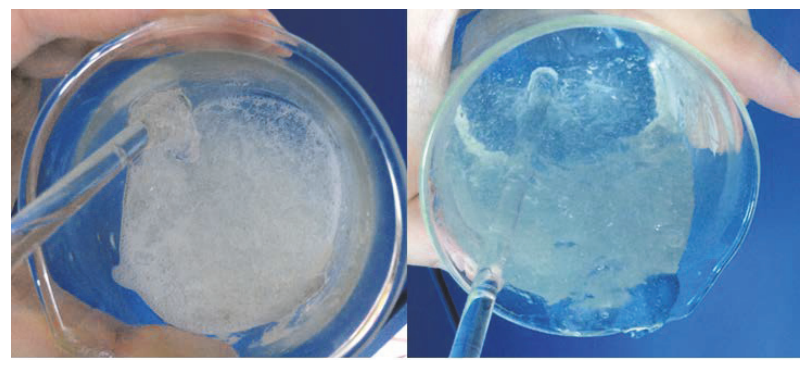

FIGURE 9: Cross-linking of guar with $500 \mathrm{ppm} \mathrm{MgCl}_{2}$ (Sample TI-4).

blockage can happen and aggravates the permeability damage. However, considering that the permeability damage was only doubled when rock permeability was reduced by about 45 times, the recycled formulation may still meet the field requirements. Nevertheless, further tests are needed to fully understand the damage resulting from the usage of recycled flowback water. 


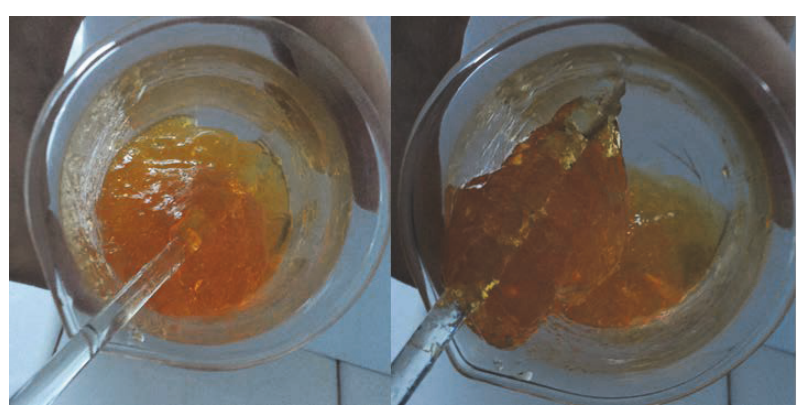

Figure 10: Cross-linking of guar with $400 \mathrm{ppm} \mathrm{FeCl}_{2}$ (Sample TI-5).

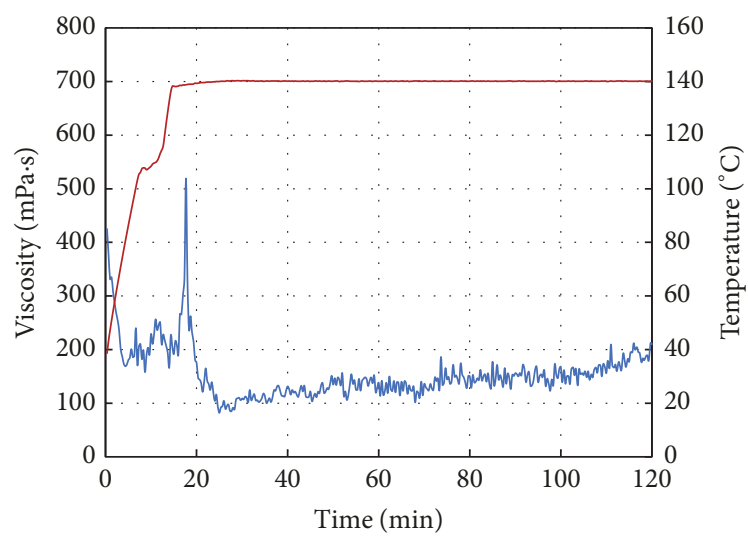

(a)

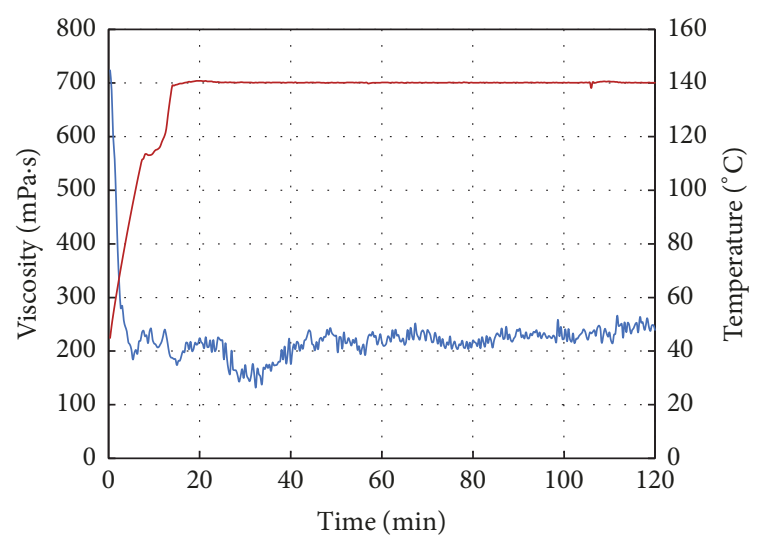

(b)

FIGURE 11: Comparison of shear resistance of the cross-linked guar synthesized using the original formulation (a) or using the recycling formulation (b) under $140^{\circ} \mathrm{C}$.

\section{Conclusions}

Effective oil/gas recovery from low-permeability reservoirs requires huge amounts of water to create complex fracture networks; in the remote desert area, water resource is scarce, and thus the recycling and reusing the flowback fluid collected from the fractured wells is crucial to ensure the sustainable development. Fracturing fluid interacts with the reservoir rock and the formation water, resulting in high contents of suspend solids and dissolved solids in the flowback fluid; this can seriously affect the gelation and cross-linking of the gel during the recycling and reusing process.

After the flowback fluid is collected from the well, its key properties and main components are firstly analyzed for designing the recycle scheme; they may include the $\mathrm{pH}$ value, the density, contents of the residual breakers, the suspended solids, and the dissolved solids of the fluid. To effectively remove the unfavorable components and reuse the favorable components for subsequent fracturing, this study established the following procedures: (1) filtering and decoloring the collected fluid to remove the suspend solids; (2) optimizing the chelating agents to shield the dissolved divalent metal ions from the formation; (3) supplementing with citric acid and cross-linking regulators to tune the $\mathrm{pH}$ value in sequence for gel cross-linking. By following this procedure, the recycled guar synthesized from the collected flowback fluid shows excellent gelation and cross-linking properties, and a better shear resistance under the reservoir temperature comparing to the original guar used for the previous fracturing. However, its residuals can still cause formation damage, and more studies are needed to fully understand this damage as well as its mitigation methods.

\section{Conflicts of Interest}

The authors declare no financial conflicts of interest regarding the publication of this paper.

\section{Acknowledgments}

This study is financially supported by the PetroChina Innovation Foundation (Grant no. 2016D-5007-0205), the National Science and Technology Major Projects of China (Grant nos. 2016ZX05051 and 2017ZX05030), and the Science Foundations of China University of Petroleum at Beijing (Grant nos. 2462015YJRC027 and 2462017YJRC031).

\section{References}

[1] EIA, Hydraulic fracturing accounts for about half of current U.S. crude oil production - Today in Energy - U.S. Energy Information Administration (EIA), http://www.eia.gov/todayinenergy/ detail.php?id=25372, 2016.

[2] EIA, Hydraulically fractured wells provide two-thirds of U.S. natural gas production, https://www.eia.gov/todayinenergy/ detail.php, 2016.

[3] Z. Rui, F. Peng, K. Ling, H. Chang, G. Chen, and X. Zhou, "Investigation into the performance of oil and gas projects," Journal of Natural Gas Science and Engineering, vol. 38, pp. 1220, 2017.

[4] G. E. King, "Hydraulic fracturing 101: what every representative, environmentalist, regulator, reporter, investor, university researcher, neighbor and engineer should know about estimating frac risk and improving frac performance in unconventional gas and oil wells," OnePetro, 2012.

[5] A. Kondash and A. Vengosh, "Water footprint of hydraulic fracturing," Environmental Science \& Technology Letters, vol. 2, no. 10, pp. 276-280, 2015.

[6] Z. Rui, J. Lu, Z. Zhang et al., "A quantitative oil and gas reservoir evaluation system for development," Journal of Natural Gas Science and Engineering, vol. 42, pp. 31-39, 2017. 
[7] L. Wang, S. Wang, R. Zhang et al., "Review of multi-scale and multi-physical simulation technologies for shale and tight gas reservoirs," Journal of Natural Gas Science and Engineering, vol. 37, pp. 560-578, 2017.

[8] L. Yu, R. Liu, and Y. Jiang, "A review of critical conditions for the onset of nonlinear fluid flow in rock fractures," Geofluids, vol. 2017, Article ID 2176932, 17 pages, 2017.

[9] B. R. Scanlon, R. C. Reedy, and J.-P. Nicot, “Comparison of water use for hydraulic fracturing for unconventional oil and gas versus conventional oil," Environmental Science \& Technology, vol. 48, no. 20, pp. 12386-12393, 2014.

[10] T. J. Gallegos, B. A. Varela, S. S. Haines, and M. A. Engle, "Hydraulic fracturing water use variability in the United States and potential environmental implications," Water Resources Research, vol. 51, no. 7, pp. 5839-5845, 2015.

[11] EIA, Initial production rates in tight oil formations continue to rise, https://www.eia.gov/todayinenergy/detail.php, 2016.

[12] J. Sun, E. S. Gamboa, D. Schechter, and Z. Rui, "An integrated workflow for characterization and simulation of complex fracture networks utilizing microseismic and horizontal core data," Journal of Natural Gas Science and Engineering, vol. 34, pp. 13471360, 2016.

[13] T. Guo, Y. Li, Y. Ding, Z. Qu, N. Gai, and Z. Rui, "Evaluation of acid fracturing treatments in shale formation," Energy \& Fuels, vol. 31, no. 10, pp. 10479-10489, 2017.

[14] J. L. Gidley, S. A. Holditch, D. E. Nierode, and W. Ralph Veatch Jr., "Recent advances in hydraulic fracturing SPE monograph series," Society of Petroleum Engineers, vol. 12, 1990.

[15] C. Lei and P. E. Clark, "Crosslinking of guar and guar derivatives," SPE Journal, vol. 12, no. 3, pp. 316-321, 2007.

[16] DOE., "Modern Shale Gas Development in the United States: A Primer," U.S. Department of Energy, 2009.

[17] A. R. Acharya, "Viscoelasticity of crosslinked fracturing fluids and proppant transport," SPE Production Engineering, vol. 3, no. 4, pp. 483-488, 1988.

[18] P. C. Harris, H. G. Walters, and J. Bryant, "Prediction of proppant transport from rheological data," SPE Production \& Operations, vol. 24, no. 4, pp. 550-555, 2009.

[19] Y. T. Hu, H. Chung, and J. E. Maxey, "What is more important for proppant transport, viscosity or elasticity?" in Proceedings of the SPE Hydraulic Fracturing Technology Conference, Society of Petroleum Engineers, The Woodlands, Tex, USA, 2015.

[20] J. Thompson and C. DeVine, "Fracturing fluid interactions with formation minerals and their subsequent effect on formation permeability," in Proceedings of the SPE Production Operations Symposium, Society of Petroleum Engineers, Oklahoma City, Okla, USA, 1995.

[21] G. Cui, S. Ren, Z. Rui, J. Ezekiel, L. Zhang, and H. Wang, "The influence of complicated fluid-rock interactions on the geothermal exploitation in the CO2 plume geothermal system," Applied Energy, 2017.

[22] B. Ihejirika, A. Dosunmu, and C. Eme, "Performance evaluation of guar gum as a carrier fluid for hydraulic fracturing," in Proceedings of the SPE Nigeria Annual International Conference and Exhibition, Society of Petroleum Engineers, Lagos, Nigeria, 2015.

[23] H. Sun, L. Li, J. Mayor, and P. Carman, "Study on abnormal viscosity development in high-TDS produced water," in Proceedings of the SPE International Symposium on Oilfield Chemistry, Society of Petroleum Engineers, The Woodlands, Tex USA, 2015.
[24] M. Alohaly, A. BinGhanim, R. Rahal, and S. Rahim, "Seawater fracturing fluid development challenges: A comparison between seawater-based and freshwater-based fracturing fluids using two types of guar gum polymers," in Proceedings of the SPE Kingdom of Saudi Arabia Annual Technical Symposium and Exhibition, Society of Petroleum Engineers, Dammam, Saudi Arabia, 2016.

[25] Z. Liu, F. Zhou, H. Qu, Z. Yang, Y. Zou, and D. Wang, "Impact of the Microstructure of Polymer Drag Reducer on Slick-Water Fracturing," Geofluids, vol. 2017, pp. 1-8, 2017.

[26] J. W. Ely, M. Fraim, A. D. Horn, and S. D. Jakhete, "Game changing technology for treating and recycling frac water," in Proceedings of the SPE Annual Technical Conference and Exhibition, Society of Petroleum Engineers, Denver, Colo, USA, 2011.

[27] M. Fraim and S. Jakhete, "Sustainable flow back and produced water treatment using a next generation electro oxidation reactor," in Proceedings of the SPE Annual Technical Conference and Exhibition, Society of Petroleum Engineers, Houston, Tex, USA, 2015.

[28] J. Drewes, T. Cath, J. Debroux, and J. Veil, Technical Assessment of Produced Water Treatment Technologies, 1st edition, 2009.

[29] P. Boschee, "Produced and flowback water recycling and reuse: economics, limitations, and technology," Oil and Gas Facilities, vol. 3, no. 1, pp. 16-21, 2015.

[30] H. Liu, X. Yang, K. Wang, Z. Yuan, R. Zhao, and Y. Zhang, "Processing and Recycling of Waste Flowback Fracturing Fluids," in Proceedings of the SPE Health, Safety, Security, Environment, Social Responsibility Conference-North America, Society of Petroleum Engineers, 2017.

[31] M. Mulder, Basic Principles of Membrane Technology, Springer, Dordrecht, Netherlands, 2nd edition, 1996.

[32] A. Alkhudhiri, N. Darwish, and N. Hilal, "Membrane distillation: a comprehensive review," Desalination, vol. 287, pp. 2-18, 2012.

[33] P. Xu and J. E. Drewes, "Viability of nanofiltration and ultralow pressure reverse osmosis membranes for multi-beneficial use of methane produced water," Separation and Purification Technology, vol. 52, no. 1, pp. 67-76, 2006.

[34] S. Mondal and S. R. Wickramasinghe, "Produced water treatment by nanofiltration and reverse osmosis membranes," Journal of Membrane Science, vol. 322, no. 1, pp. 162-170, 2008.

[35] Z. Rui, C. Li, F. Peng et al., "Development of industry performance metrics for offshore oil and gas project," Journal of Natural Gas Science and Engineering, vol. 39, pp. 44-53, 2017.

[36] E. Neyens and J. Baeyens, "A review of classic Fenton's peroxidation as an advanced oxidation technique," Journal of Hazardous Materials, vol. 98, no. 1-3, pp. 33-50, 2003.

[37] J. J. Pignatello, E. Oliveros, and A. MacKay, "Advanced oxidation processes for organic contaminant destruction based on the Fenton reaction and related chemistry," Critical Reviews in Environmental Science and Technology, vol. 36, no. 1, pp. 1-84, 2006.

[38] S. Liu, X. Lei, C. Feng, and C. Hao, "Estimation of subsurface formation temperature in the Tarim Basin, northwest China: implications for hydrocarbon generation and preservation," International Journal of Earth Sciences, vol. 105, no. 5, pp. 13291351, 2016.

[39] H. Zhang, K. Qiu, J. Fuller, G. Yin, F. Yuan, and S. Chen, "Geomechanical-evaluation enabled successful stimulation of a high-pressure/high-temperature tight gas reservoir in Western China," SPE Drilling \& Completion, vol. 30, no. 04, pp. 274-294, 2016. 
[40] Z. Rui, G. Han, H. Zhang, S. Wang, H. Pu, and K. Ling, "A new model to evaluate two leak points in a gas pipeline," Journal of Natural Gas Science and Engineering, vol. 46, pp. 491-497, 2017.

[41] T. Liang, S. H. Achour, R. A. Longoria, D. A. DiCarlo, and Q. P. Nguyen, "Flow physics of how surfactants can reduce water blocking caused by hydraulic fracturing in low permeability reservoirs," Journal of Petroleum Science and Engineering, vol. 157, pp. 631-642, 2017.

[42] T. Liang, R. A. Longoria, J. Lu, Q. P. Nguyen, and D. A. DiCarlo, "Enhancing hydrocarbon permeability after hydraulic fracturing: laboratory evaluations of shut-ins and surfactant additives," SPE Journal, vol. 22, no. 4, pp. 1011-1023, 2017.

[43] T. Liang, F. Zhou, J. Lu, D. DiCarlo, and Q. Nguyen, "Evaluation of wettability alteration and IFT reduction on mitigating water blocking for low-permeability oil-wet rocks after hydraulic fracturing," Fuel, vol. 209, pp. 650-660, 2017.

[44] G. Naval and S. Shah, "A rheological criterion for fracturing fluids to transport proppant during a stimulation treatment," in Proceedings of the SPE Annual Technical Conference and Exhibition, Society of Petroleum Engineers, New Orleans, La, USA, 2001.

[45] A. M. Gomaa, D. V. Gupta, and P. S. Carman, "Proppant transport? viscosity is not all it's cracked up to be," in Proceedings of the SPE Hydraulic Fracturing Technology Conference, The Woodlands, Tex, USA, 2015. 

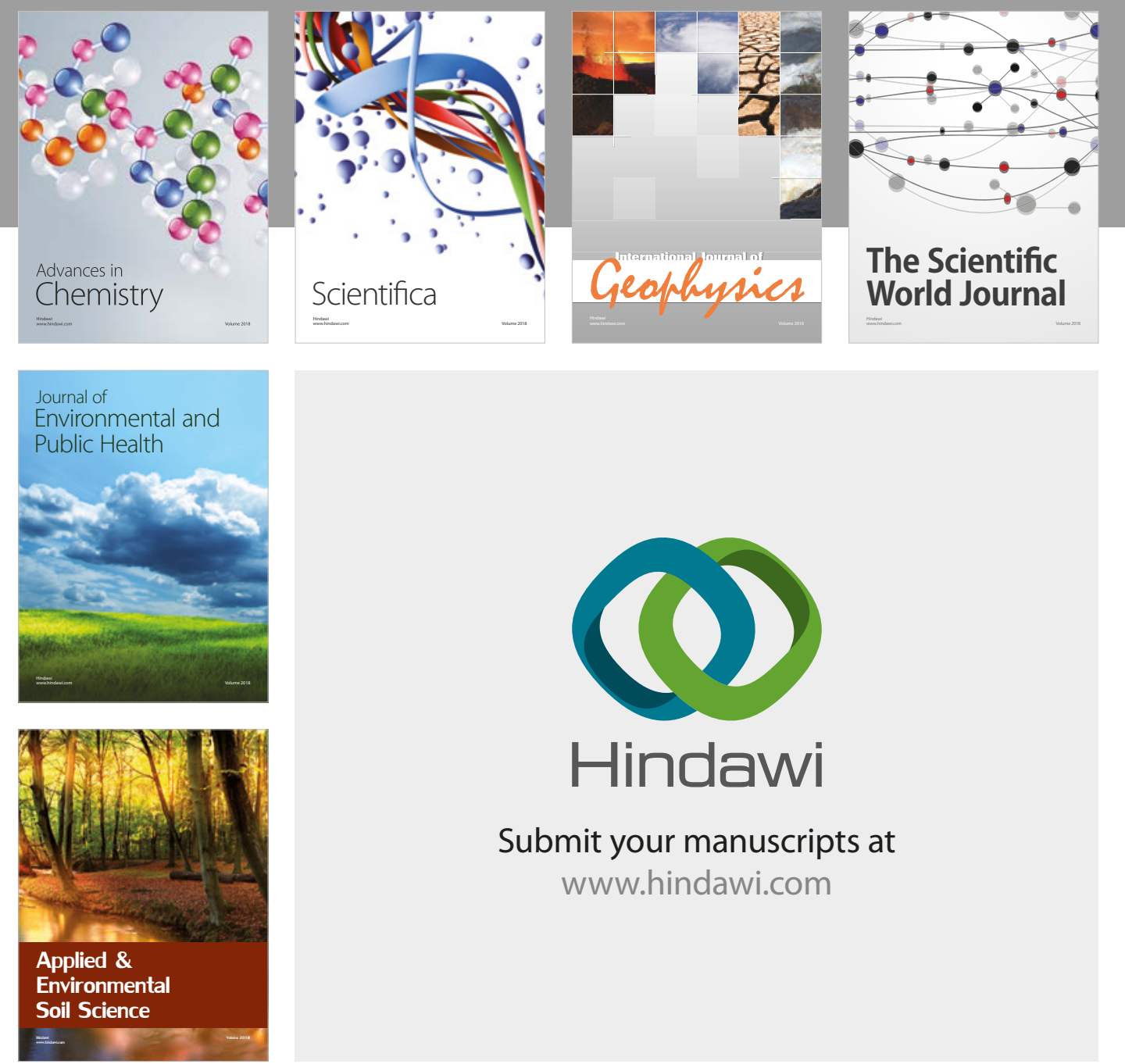

The Scientific

\section{World Journal}
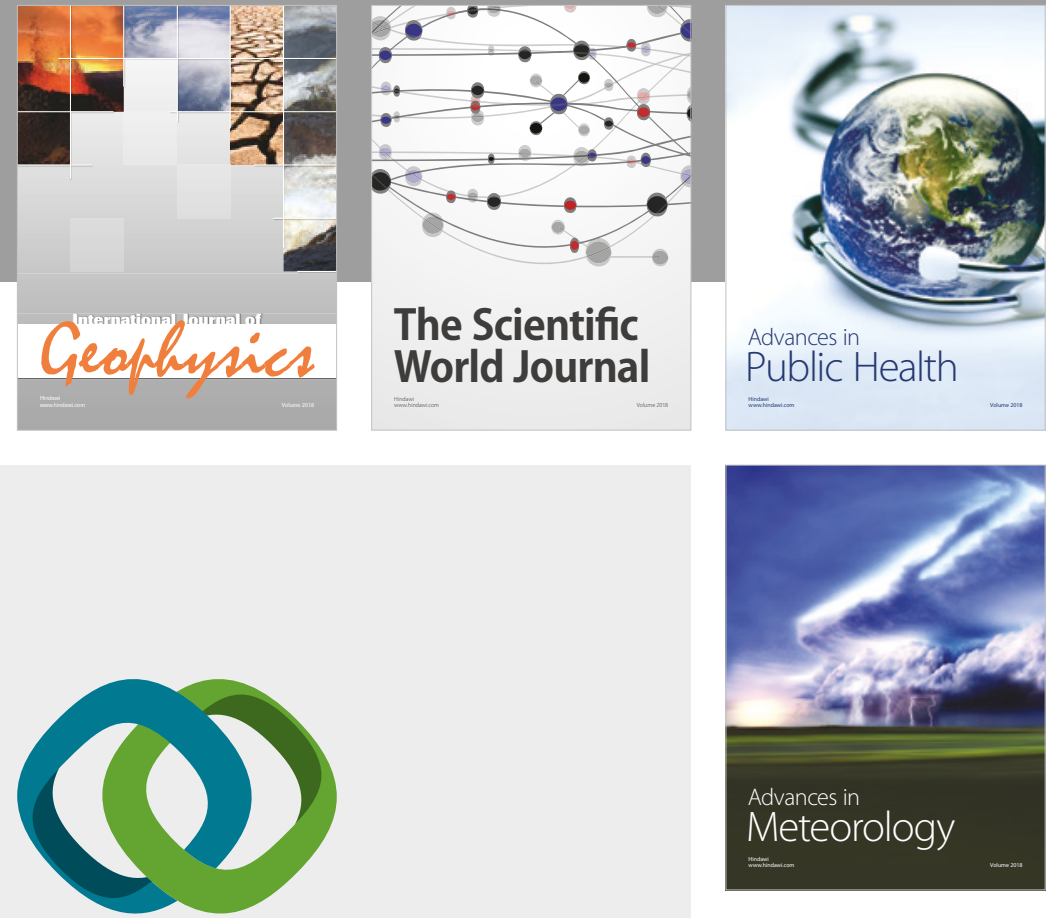

Advan

Public Health

\section{Hindawi}

Submit your manuscripts at

www.hindawi.com
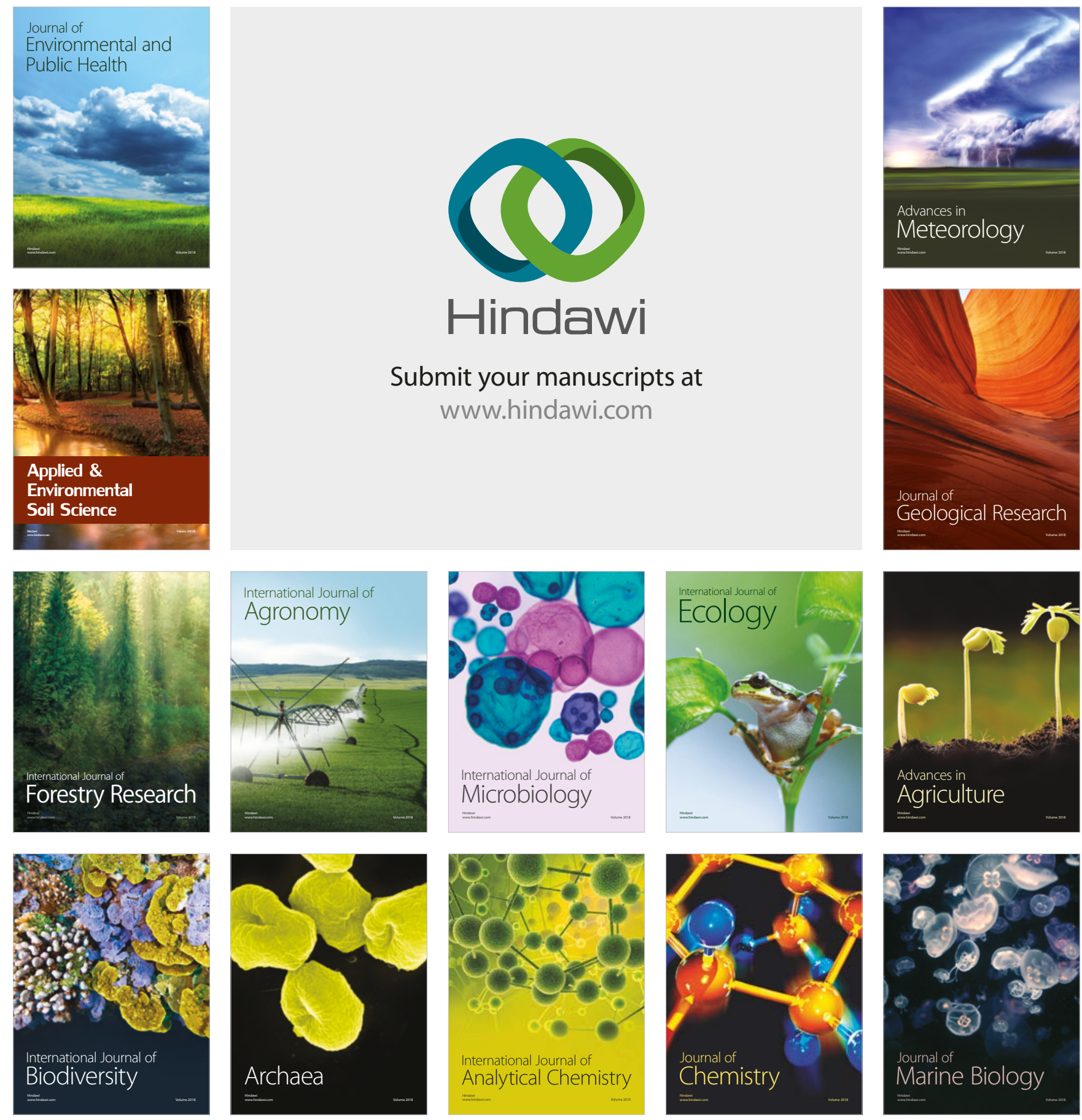